\title{
Article \\ Effect of $N$-Acetylcysteine Administration on 30-Day Mortality in Critically Ill Patients with Septic Shock Caused by Carbapenem-Resistant Klebsiella pneumoniae and Acinetobacter baumannii: A Retrospective Case-Control Study
}

\author{
Alessandra Oliva ${ }^{1,2, * \mathbb{D}}$, Alessandro Bianchi ${ }^{1}$, Alessandro Russo ${ }^{1} \mathbb{D}$, Giancarlo Ceccarelli ${ }^{1} \mathbb{D}^{\mathbb{D}}$, Francesca Cancelli $^{1}$, \\ Fulvio Aloj ${ }^{2}$, Danilo Alunni Fegatelli ${ }^{3}$, Claudio Maria Mastroianni ${ }^{1}$ (D) and Mario Venditti ${ }^{1}$ (D) \\ 1 Department of Public Health and Infectious Diseases, Sapienza University of Rome, 00185 Rome, Italy; \\ alessandro.bianchi@uniroma1.it (A.B.); alessandro.russo1982@gmail.com (A.R.); \\ giancarlo.ceccarelli@uniroma1.it (G.C.); francesca.cancelli@uniroma1.it (F.C.); \\ claudio.mastroianni@uniroma1.it (C.M.M.); mario.venditti@uniroma1.it (M.V.) \\ 2 IRCCS Neuromed, Istituto Neurologico Mediterraneo, 86077 Pozzilli (IS), Italy; aloj@neuromed.it \\ 3 Department of Statistical Science, Sapienza University of Rome, 00185 Rome, Italy; \\ danilo.alunnifegatelli@uniroma1.it \\ * Correspondence: alessandra.oliva@uniroma1.it
}

check for

updates

Citation: Oliva, A.; Bianchi, A.; Russo, A.; Ceccarelli, G.; Cancelli, F.; Aloj, F; Alunni Fegatelli, D.;

Mastroianni, C.M.; Venditti, M. Effect of $\mathrm{N}$-Acetylcysteine Administration on 30-Day Mortality in Critically Ill Patients with Septic Shock Caused by Carbapenem-Resistant Klebsiella pneumoniae and Acinetobacter baumannii: A Retrospective Case-Control Study. Antibiotics 2021, 10, 271. https://doi.org/10.3390/ antibiotics10030271

Academic Editor: Pavel Bostik

Received: 21 January 2021

Accepted: 5 March 2021

Published: 8 March 2021

Publisher's Note: MDPI stays neutral with regard to jurisdictional claims in published maps and institutional affiliations.

Copyright: ( $\odot 2021$ by the authors Licensee MDPI, Basel, Switzerland. This article is an open access article distributed under the terms and conditions of the Creative Commons Attribution (CC BY) license (https:// creativecommons.org/licenses/by/ $4.0 /)$.

\begin{abstract}
Carbapenem-resistant Klebsiella pneumoniae (CR-Kp) and Acinetobacter baumannii (CR-Ab) represent important cause of severe infections in intensive care unit (ICU) patients. N-Acetylcysteine (NAC) is a mucolytic agent with antioxidant and anti-inflammatory properties, showing also invitro antibacterial activity. Aim was to evaluate the effect on 30-day mortality of the addition of intravenous NAC to antibiotics in ICU patients with CR-Kp or CR-Ab septic shock. A retrospective, observational case:control study (1:2) in patients with septic shock caused by CR-Kp or CR-Ab hospitalized in two different ICUs was conducted. Cases included patients receiving NAC plus antimicrobials, controls included patients not receiving NAC. Cases and controls were matched for age, SAPS II, causative agent and source of infection. No differences in age, sex, SAPS II score or time to initiate definitive therapy were observed between cases and controls. Pneumonia and bacteremia were the leading infections. Overall, mortality was $48.9 \%$ (33.3\% vs. $56.7 \%$ in cases and controls, $p=0.05)$. Independent risk factors for mortality were not receiving NAC $(p=0.002)$ and CR-Ab $(p=0.034)$ whereas therapy with two in-vitro active antibiotics $(p=0.014)$ and time to initial definite therapy $(p=0.026)$ were protective. NAC plus antibiotics might reduce the 30-day mortality rate in ICU patients with CR-Kp and CR-Ab septic shock.
\end{abstract}

Keywords: carbapenem-resistant Klebsiella pneumoniae; carbapenem-resistant Acinetobacter baumannii; $\mathrm{N}$-acetylcysteine; septic shock; critically ill patients

\section{Introduction}

Carbapenem-resistant Klebsiella pneumoniae (CR-Kp) and Acinetobacter baumannii (CR$\mathrm{Ab}$ ) represent nowadays an important cause of severe infections in intensive care unit (ICU) patients and mortality rates are significantly associated to septic shock [1-6]. Protective factors that influence the clinical outcome include early appropriate antibiotic treatment, adequate source control and number of in-vitro active antimicrobials, whereas septic shock caused by CR-Ab might exhibit a mortality rate up to $60 \%$ [6,7]. Therefore, in the context of increasing antimicrobial resistance and restricted therapeutic options typical of the contemporary era, there is a growing scientific interest on finding possible therapeutic adjuvants for sepsis and septic shock [8-11]. Since septic shock is characterized by excessive and unbalanced production of pro-inflammatory cytokines, reactive oxygen species and a marked alteration of circulation, compounds able to counteract these effects might find a rationale in the treatment of this condition [12-17]. 
$\mathrm{N}$-Acetylcysteine (NAC) is a mucolytic agent with antioxidant and anti-inflammatory properties, commonly used for the treatment of acetaminophen overdose or respiratory conditions with high mucus production [18-20]. Beyond this, NAC showed also in-vitro activity against several bacteria including multi-drug resistant (MDR) ones and viruses and demonstrated a synergistic interaction with antibiotics or antivirals [21-30]. In addition, animal models showed improvement of organ damage and a reduction of microvascular dysfunction following NAC administration in endotoxin-induced shock [12,31], rendering this compound attractive for the clinical use as a therapeutic adjuvant in case of infections.

To date, clinical studies evaluating NAC in septic shock gave conflicting results; however, most of them were not recent [32-37]. On the other hand, a recent randomized clinical trial investigating the effect of different anti-oxidants as adjuvants in septic shock showed that NAC was able to improve antioxidant capacity [38].

Besides the common use of NAC in the clinical practice, currently in some Italian centers including the ICU of IRCCS Neuromed (Pozzilli, Italy), intravenous NAC is routinely administered in critically ill patients with respiratory conditions characterized by excessive and/or thick mucus production.

Therefore, based on these premises, the purpose of the study was to evaluate the effect on 30-day mortality of the addition of intravenous NAC to antibiotic therapy in ICU patients with septic shock caused by CR-Kp or CR-Ab.

\section{Results}

During the study period, there were 41 cases of patients who had septic shock caused by CR-Kp or CR-Ab treated with NAC. Eleven out of 41 (26.8\%) were excluded from the study: central nervous system infections (four cases), no sufficient data (four cases) or no matched controls (three cases). Eventually, 90 patients were enrolled in the study (30 cases and 60 matched controls) (Figure 1).

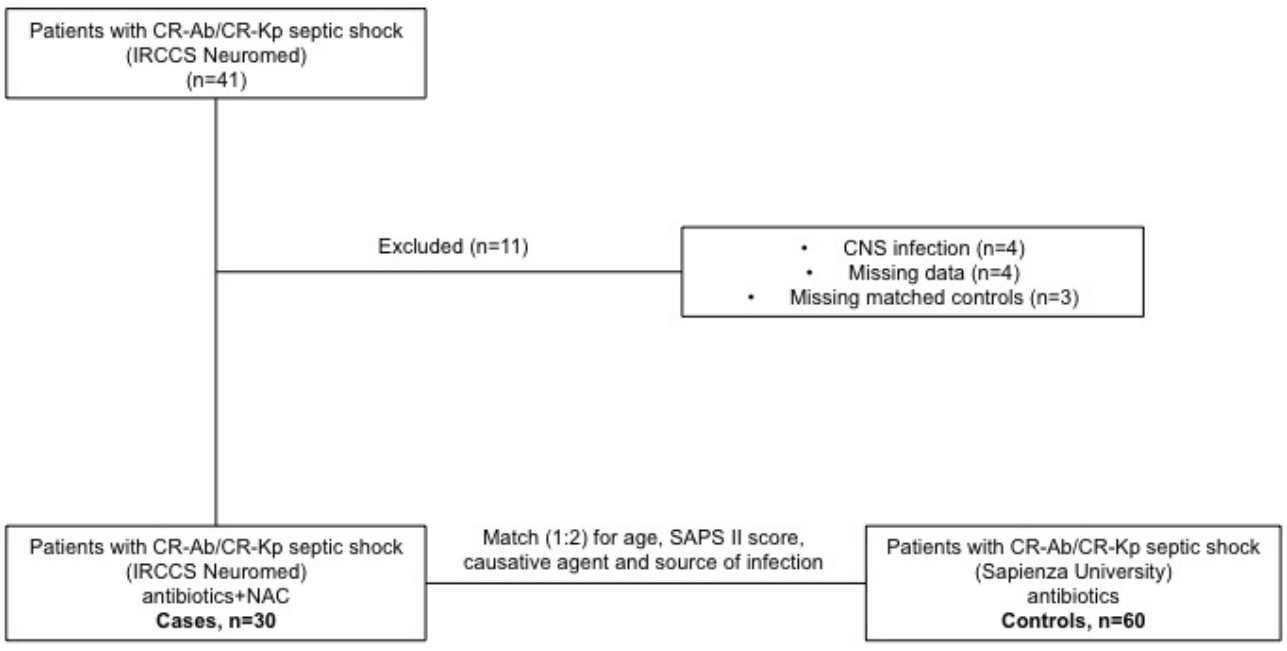

Figure 1. Flow-chart of the study.

Mean age was 58.1 and 59.2 years in case and control groups, respectively. $80 \%$ of cases and $68.3 \%$ of controls were male. SAPS II was 35.3 and 38.6 in cases and controls, respectively. Previous antibiotic therapy was recorded in $63.3 \%$ and $48.3 \%$ of cases and controls, respectively, whereas a previous CR-Kp or CR-Ab colonization was found in $43.3 \%$ and $28.3 \%$ of cases and controls, respectively. Length of ICU stay was statistically significant longer in cases than in controls (51.4 vs. 27.8 days, $p<0.001$ ). Study population characteristics are shown in Table 1. 
Table 1. Characteristics of patients with septic shock caused by carbapenem-resistant Klebsiella pneumoniae (CR-Kp) and Acinetobacter baumannii (CR-Ab).

\begin{tabular}{|c|c|c|c|}
\hline & $\begin{array}{l}\text { Cases }^{\circ} \\
n=30\end{array}$ & $\begin{array}{c}\text { Controls }^{\circ} \\
n=60\end{array}$ & $p$-Value \\
\hline Age, years (mean \pm SD) & $58.1 \pm 17.7$ & $59.2 \pm 14.19$ & * \\
\hline Male sex, n (\%) & $24(80)$ & $41(68.3)$ & 0.32 \\
\hline SAPS II & $35.33 \pm 17.7$ & $38.57 \pm 11.5$ & * \\
\hline Lenght of ICU stay, days (mean \pm SD) & $51.4 \pm 27.9$ & $27.8 \pm 20$ & $<0.0001$ \\
\hline Previous (90-d) hospitalization, n (\%) & $14(46.6)$ & $21(35)$ & 0.36 \\
\hline Previous (90-d) ICU admission, n (\%) & $4(13.3)$ & $6(10)$ & 0.72 \\
\hline Previous (90-d) surgery, n (\%) & $14(43.3)$ & $17(28.3)$ & 0.16 \\
\hline Previous $(90-d)$ antibiotic therapy, n (\%) & $19(63.3)$ & $29(48.3)$ & 0.26 \\
\hline Previous colonization with CR-Kp or CR-Ab, n (\%) & $13(43.3)$ & $17(28.3)$ & 0.16 \\
\hline $\begin{array}{c}\text { Comorbidities, } \mathbf{n}(\mathbf{\%}) \\
\text { - chronic liver disease } \\
\text { - neoplasm } \\
\text { - diabetes mellitus } \\
\text { - cardiovascular diseases } \\
\text { - chronic renal failure } \\
\text { - COPD }\end{array}$ & $\begin{array}{c}6(20) \\
6(20) \\
6(20) \\
18(60) \\
0(0) \\
3(10)\end{array}$ & $\begin{array}{c}7(11.6) \\
2(3.3) \\
15(25) \\
19(31.6) \\
2(3.3) \\
11(18.3)\end{array}$ & $\begin{array}{l}0.34 \\
0.01 \\
0.79 \\
0.01 \\
0.55 \\
0.37\end{array}$ \\
\hline $\begin{array}{c}\text { Causes of ICU admission, } \mathbf{n}(\mathbf{\%}) \\
\text { - respiratory failure } \\
\text { - septic shock } \\
\text { - stroke } \\
\text { - post-surgery } \\
\text { - trauma } \\
\text { - cardiac arrest }\end{array}$ & $\begin{array}{c}6(20) \\
3(10) \\
12(40) \\
6(20) \\
2(6.6) \\
1(3.3)\end{array}$ & $\begin{array}{l}20(33.3) \\
14(23.3) \\
4(6.6) \\
7(11.6) \\
9(15) \\
6(10)\end{array}$ & $\begin{array}{c}0.22 \\
0.16 \\
0.0002 \\
0.34 \\
0.32 \\
0.41\end{array}$ \\
\hline $\begin{array}{c}\text { Source of infection, } \mathbf{n}(\mathbf{\%}) \\
\text { - pneumonia } \\
\text { - primary bacteremia }\end{array}$ & $\begin{array}{l}20(66.7) \\
10(33.3)\end{array}$ & $\begin{array}{l}40(66.7) \\
20(33.3)\end{array}$ & * \\
\hline $\begin{array}{c}\text { Causative agent, } \mathbf{n}(\%) \\
\text { - CR-Kp } \\
\text { - CR-Ab }\end{array}$ & $\begin{array}{l}18(60) \\
12(40)\end{array}$ & $\begin{array}{l}36(60) \\
24(40)\end{array}$ & * \\
\hline Colistin-resistant strains, n (\%) & $8(26.7)$ & $29(31.7)$ & 0.54 \\
\hline Adequate source control, n (\%) & $10(33.3)$ & $31(51.6)$ & 0.12 \\
\hline $\begin{array}{l}\text { Number of antibiotics used as definitive therapy, n (\%) } \\
\qquad \begin{array}{c}- \text { no definite therapy } \\
-1 \text { antibiotic } \\
-2 \text { antibiotics } \\
-3 \text { antibiotics } \\
-4 \text { antibiotics }\end{array}\end{array}$ & $\begin{array}{c}1(3.4) \\
0(0) \\
12(40) \\
13(43.3) \\
4(13.3)\end{array}$ & $\begin{array}{c}1(1.7) \\
5(8.3) \\
19(31.6) \\
28(46.7) \\
7(11.7)\end{array}$ & $\begin{array}{l}0.99 \\
0.16 \\
0.48 \\
0.82 \\
0.99\end{array}$ \\
\hline $\begin{array}{l}\text { Type of antimicrobial combinations, } \mathbf{n}(\mathbf{\%}) \\
\text { - Carbapenem-containing regimen } \\
\text { - Colistin-containing regimen } \\
\text { - Tigecycline-containing regimen } \\
\text { - Aminoglycoside-containing regimen } \\
\text { - Rifampin-containing regimen }\end{array}$ & $\begin{array}{c}22(73.3) \\
24(80) \\
7(23.3) \\
6(20) \\
2(6.7)\end{array}$ & $\begin{array}{c}44(73.3) \\
33(55) \\
33(55) \\
8(13.33) \\
13(20)\end{array}$ & $\begin{array}{c}0.99 \\
0.02 \\
0.007 \\
0.53 \\
0.12\end{array}$ \\
\hline $\begin{array}{l}\geq 2 \text { in-vitro active antibiotics within } 24 \mathrm{~h} \\
\text { from septic shock, } \mathrm{n}(\%)\end{array}$ & $5(16.7)$ & $14(23.3)$ & 0.58 \\
\hline$\geq 2$ in-vitro active antibiotics definitive, $n(\%)$ & $6(20)$ & $16(26.7)$ & 0.60 \\
\hline Time to initial definitive therapy, days (mean \pm SD) & $2.7 \pm 0.4$ & $2.65 \pm 0.2$ & 0.86 \\
\hline NAC dosage, mg/die (mean \pm SD) & $\begin{array}{c}1520 \pm 504 \\
(1200-3000)\end{array}$ & NA & \\
\hline Length of antibiotic therapy, days (mean \pm SD) & $15.1 \pm 7.9$ & $12.3 \pm 8.3$ & 0.12 \\
\hline Length of NAC therapy, days (mean \pm SD) & $16.6 \pm 7.1$ & NA & \\
\hline Adverse effects of NAC therapy, n(\%) & $0(0)$ & NA & \\
\hline $\begin{array}{l}\text { Outcome, n (\%) } \\
\text { - 7-day mortality } \\
\text { - 14-day mortality } \\
\text { - 30-day mortality }\end{array}$ & $\begin{array}{c}4(13.3) \\
6(20) \\
10(33.3)\end{array}$ & $\begin{array}{c}15(25) \\
19(31.7) \\
34(56.7)\end{array}$ & $\begin{array}{c}0.18 \\
0.32 \\
0.051\end{array}$ \\
\hline
\end{tabular}

${ }^{\circ}$ : Cases included patients receiving intravenous NAC in combination with antimicrobials, controls included patients not receiving NAC. Data collection for cases was blinded for the outcome. *: Cases and controls were matched for age, SAPS II, source of infection and causative agent. ICU: Intensive Care Unit. CR-Kp: Carbapenem-resistant Klebsiella pneumoniae; CR-Ab: Carbapenem-resistant Acinetobacter baumannii; COPD: Chronic Obstructive Pulmonary Disease. NA: not applicable. 
In both groups pneumonia was the most frequent source of infection (66.7\%), followed by primary bacteremia (33.3\%). As for causative agent, $60 \%$ and $40 \%$ of patients had a septic shock caused by CR-Kp and CR-Ab, respectively. Colistin resistant strains represented $26.7 \%$ and $31.7 \%$ of isolates in case and control group, respectively, without statistical differences.

Combination therapy was used in almost all patients. In case group, 40\% (12/30) of patients received a combination of two antibiotics, $43.3 \%(13 / 30)$ a combination of three antibiotics and $13.3 \%(4 / 30)$ a combination of four antibiotics. A definitive antibiotic regimen containing colistin and/or carbapenem was the most commonly used, respectively in $80 \%$ and $73.3 \%$ of cases, followed by regimens containing tigecycline $(23.3 \%)$ and aminoglycoside $(20 \%)$. In control group, $8.3 \%(5 / 60)$ of patients received monotherapy, $31.6 \%(19 / 60)$ of patients received a combination of two antibiotics, $46.7 \%(28 / 60)$ a combination of three antibiotics and $11.7 \%(7 / 60)$ a combination of four antibiotics. A definitive antibiotic regimen containing carbapenem $(73.3 \%)$ was the most used, followed by regimens containing colistin (55\%), tigecycline (55\%) and aminoglycoside (13.3\%). Rifampin-containing regimens were used in $6.7 \%$ and $20 \%$ in cases and controls, respectively $(p=0.12)$. No differences were observed in the two study groups regarding the use of carbapenems, while colistin-containing regimen was used more frequently in cases than in controls $(p=0.02)$. Conversely, tigecycline-containing regimen was used more frequently in controls $(p=0.007)$ (Table 1).

Time to initiate definitive antibiotic therapy was 2.7 days for both groups. Length of antibiotic therapy was similar in the two groups, 15.1 days for cases and 12.3 days for controls $(p=0.12)$.

In the first $24 \mathrm{~h}$ from septic shock onset, treatment with two or more antibiotics displaying in vitro activity was reported in $16.7 \%$ of cases and in $23.3 \%$ of controls and definitive therapy with two or more antibiotics displaying in vitro activity was reported in $20 \%$ of cases and $26.7 \%$ of controls, without statistical differences. The mean $( \pm$ SD) administered NAC dosage was $1520 \pm 504 \mathrm{mg} /$ die, ranging from 1200 to $3000 \mathrm{mg} /$ die, according to treating physicians. Mean $( \pm \mathrm{SD})$ duration of NAC treatment was $16.6 \pm 7.1$ days and no adverse events were recorded during NAC administration.

Overall 7 -day ( $13.3 \%$ in cases, $25 \%$ in controls) and 14 -day $(20 \%$ in cases, $31.7 \%$ in controls) mortality rates were lower in cases than controls, without reaching the statistical significance. On the other hand, the 30-day mortality rate (48.9\%) was lower in cases than controls at univariate analysis ( $33.3 \%$ in cases versus $56.7 \%$ in controls, $p=0.05)$. Figure 2 shows the 30-day overall survival rate in cases and controls.

In addition, mortality was higher when septic shock was caused by CR-Ab [22/36 (61.1\%) versus 22/54 (40.7\%) in CR-Ab and CR-Kp, respectively].

At the univariate analysis, risk factor for mortality were age $(p=0.01)$, CR-Ab infection $(p<0.001)$, not receiving NAC $(p=0.05)$, whereas time to initiate definitive therapy $(p=0.017)$ and definitive therapy with two or more antibiotics displaying in vitro activity $(p=0.005)$ were protective.

At the multivariate analysis, independent risk factors for mortality were not receiving NAC (HR: 3.6; 95\% CI, 1.59 to 8.22; $p=0.002$ ) and CR-Ab infection (HR: 2.8; 95\% CI, 1.08 to $7.24 ; p=0.034$ ); whereas time to initiate definitive therapy (HR: $0.83 ; 95 \% \mathrm{CI}, 0.70$ to 0.98 ; $p=0.026)$ and definitive therapy with two or more antibiotics displaying in vitro activity (HR: $0.21 ; 95 \%$ CI, 0.06 to $0.73 ; p=0.014$ ) were protective, regardless of age, sex, SAPS II score, source of infection or the type of antibiotics used as definitive therapy (Table 2). 


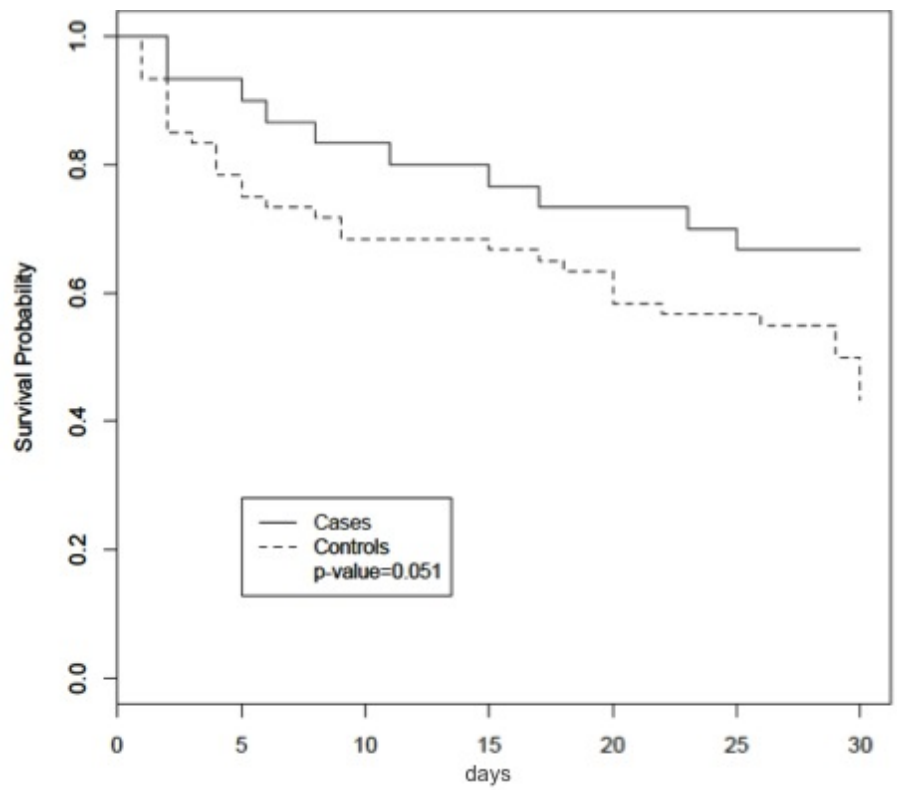

Figure 2. Overall 30-day survival rate in patients with carbapenem-resistant K. pneumoniae or A. baumannii septic shock receiving antibiotics plus intravenous NAC (cases, $\mathrm{n}=30$ ) or antibiotics only (controls, $\mathrm{n}=60$ ).

Table 2. Indipendent risk factors for 30-day mortality of patients with septic shock caused by carbapenem-resistant Klebsiella pneumoniae and Acinetobacter baumannii.

\begin{tabular}{|c|c|c|c|c|c|c|}
\hline \multirow{2}{*}{ Variable } & \multicolumn{3}{|c|}{ Univariate Analysis } & \multicolumn{3}{|c|}{ Multivariate Analysis } \\
\hline & HR & $95 \% \mathrm{CI}$ & $p$-Value & HR & $95 \%$ CI & $p$-Value \\
\hline $\begin{array}{c}\text { Controls } \\
\text { (not receiving NAC) }\end{array}$ & 1.99 & $0.98-4.04$ & 0.05 & 3.61 & $1.59-8.22$ & 0.002 \\
\hline Sex & 0.88 & $0.46-1.68$ & 0.70 & 1.35 & $0.68-2.69$ & 0.38 \\
\hline Age & 1.02 & $1.00-1.05$ & 0.015 & 1.02 & $0.99-1.05$ & 0.17 \\
\hline SAPS II & 1.01 & $0.99-1.03$ & 0.30 & 1.01 & $0.98-1.05$ & 0.25 \\
\hline $\mathrm{CR}-\mathrm{Ab}$ & 3.29 & $1.81-6.00$ & $<0.001$ & 2.79 & $1.07-7.24$ & 0.03 \\
\hline$\geq 2$ in-vitro active antibiotics & 0.22 & $0.08-0.63$ & 0.005 & 0.21 & $0.06-0.73$ & 0.014 \\
\hline Number of antibiotics in definitive therapy & 0.69 & $0.47-1.03$ & 0.07 & 0.65 & $0.39-1.09$ & 0.10 \\
\hline Pneumonia & 1.74 & $0.86-3.53$ & 0.12 & 0.79 & $0.32-1.94$ & 0.62 \\
\hline Use of colistin & 0.94 & $0.51-1.73$ & 0.86 & 0.50 & $0.19-1.32$ & 0.16 \\
\hline Time to definitive antibiotic therapy & 0.81 & $0.69-0.96$ & 0.01 & 0.82 & $0.69-0.97$ & 0.026 \\
\hline
\end{tabular}

NAC: N-acetylcysteine; CR-Ab: Carbapenem-resistant Acinetobacter baumannii. SAPS II: Simplified Acute Physiology Score II. CI: Confidence interval.

\section{Discussion}

Septic shock is associated with high mortality rate, particularly when caused by CR Kp or $\mathrm{CR} \mathrm{Ab}[5,6,39,40]$ being the latter associated to a worse prognosis [39]. To the best of our knowledge, this case-control study analyzed for the first time the effects on 30-day mortality of NAC administration in addition to antibiotic therapy in critically ill patients with septic shock due to CR-Kp or CR-Ab. With this regard, we were able to demonstrate that in patients who received NAC, 30-day mortality was significantly lower than in controls.

NAC is the N-acetyl derivative of the amino acid L-cysteine with anti-oxidant properties thanks to the increase of glutathione in the body, able to reduce free oxygen radicals and to inhibit the effect of pro-inflammatory cytokines [41]. Additionally, NAC has also a vasodilatation activity on microcirculation that improves locoregional blood flow [17]. All 
of the abovementioned phenomena may have important implications in the setting of a dysregulated host response to infection with a high release of pro-inflammatory cytokines, reactive oxygen species and a profound alteration of microcirculation, as it occurs in septic shock [13-16]. In animal models, it was demonstrated that NAC ameliorates endotoxin shock-induced organ damage through the reduction of free radicals and inflammatory cytokines production [31]. Of note, this effect was observed when NAC was administered either as a pre-treatment or as a post-treatment drug [31] Furthermore, several studies demonstrated in vitro activity of NAC against a large variety of microorganisms, including K. pneumoniae and A. baumannii $[21-23,26]$. In particular, preliminary results from our group showed that NAC was highly synergic with meropenem against clinical strains of $\mathrm{CR}-\mathrm{Kp}$ and $\mathrm{CR}-\mathrm{Ab}$ whereas Pollini et al. found a remarkable synergism of colistin/NAC combinations against $\mathrm{CR}-\mathrm{Ab}[21,22,26]$.

However, in spite of the promising results from both in vitro and animal studies, human studies might suggest otherwise. On one side, some NAC studies in patients with sepsis showed encouraging results as far as improved tissue oxygenation and hepatosplanchnic flow, decreased oxidative damage and reduction in IL-8 blood concentrations are concerned [32-36]. On the other hand, a meta-analysis of 41 randomized clinical trials investigating the role of NAC on clinical outcomes in sepsis patients showed no benefit on mortality, length of stay, duration of mechanical ventilation, and incidence of new organ failure with early or late NAC administration [37]. Rather, the latter was associated with hemodynamic instability. As a consequence, the authors concluded that clinicians should not routinely use intravenous NAC in sepsis. The conclusion was confirmed even after subgroups analysis between studies focusing on systemic inflammatory response syndrome or sepsis/septic shock. However, when looking in depth within the meta-analysis, all studies referred to the period 1991-2009 and heterogeneity among study populations was also observed [37]. Furthermore, in almost all studies NAC was given after the sepsis syndrome had been established, potentially too late to be beneficial on outcome. Additionally, another potentially important concern was that high doses have been used in the majority of the abovementioned randomized clinical trials, namely $150 \mathrm{mg} / \mathrm{kg}$, which may allow formation of toxic intermediate molecules interfering with potential benefits of NAC therapy [42].

Conversely, in our study NAC was administered at the very early phase of infection before the development of sepsis syndrome and the mean dosage of NAC (1520 mg/die) was lower than that used in previous study, thus reducing the risk of toxic intermediates production.

Finally, a recent randomized clinical trial investigating the effect of different antioxidants in septic shock showed that NAC was able to improve antioxidant capacity, in the absence of significant adverse reactions or side effects [38].

Early antibiotic therapy represents a cornerstone of critical care management in septic shock patients $[4,40,43-46]$. Accordingly, in our study a protective effect on mortality was related to the time to initiate definitive therapy, defined as the time between infection onset and initial definitive in vitro active therapy. Combination therapy was the most used treatment in our study; however, previous studies suggested that the key factor for decreasing the mortality is not the number of drugs used but rather the administration of at least two in vitro-active antibiotics, in particular for CR-Kp [6,46,47]. Treatment with two or more in vitro-active antibiotics is difficult to achieve in the presence of MDR bacteria because limited options are available to treat these infections, especially for CR-Ab. In fact, in our study only $36.7 \%$ of patients were treated with two or more antibiotics showing in vitro activity against the isolates and this probably explains the high mortality rates observed in our population, which is, however, similar to that reported in the literature [6]. Nevertheless, treatment with two or more in vitro-active antibiotics was associated with lower mortality. 
Although a difference was observed in the two study groups regarding the use of regimens containing colistin and tigecycline, with the former more frequently used in cases than controls, this did not affect overall mortality.

In our study, 30-day mortality for CR-Ab was higher than that observed for CR-Kp. The impact of CR-Ab on clinical outcome was also highlighted in multivariable analysis, thus confirming the recent literature data, which showed a mortality rate of up to $60 \%$ and $40 \%$ in the presence of septic shock caused by CR-Ab and CR-Kp, respectively $[5,6,48]$.

Our study has some limitations that should be acknowledged. First, the retrospective nature of the study is an intrinsic limitation of this analysis. Second, the sample size is relatively low and included all patients with septic shock caused by CR-Kp or CR-Ab observed in the two ICUs, without a sample size calculation. Therefore, the results of our study might be considered preliminary and further multicenter prospective studies are needed to confirm our findings. Third, cases and controls came from two distinct cohorts of patients and therefore differences could be related to intrinsic differences between populations and microorganism, despite the extensive patients' matching (age, SAPS II score, causative agent and source of infection). However, we were confident that the potential differences were minimized by the fact that both ICUs had a dedicated Infectious Diseases consultant who was in charge for the treatment of all patients and who belonged to the same well-established consultation system. Consequently, the Infectious Diseases consultants had the same diagnostic and therapeutic approach towards patients admitted to these 2 ICUs (Supplementary Figure S1). Fourth, NAC was not administered in all cases at the same dosage and timing and consequently the results need to be interpreted cautiously. Lastly, since study population included mainly patients who had pneumonia, conclusions should mostly apply to ICU patients with pneumonia-associated septic shock caused by CR-Kp and CR-Ab. An additional limitation was the lack of oxidative markers (i.e nitrate/nitrite ratio, glutathione) measurements before and after NAC therapy.

Nevertheless, we believe that the present investigation has some important strenghts, which might have contributed to bias reduction, such as: (i) patients were matched for several variables, which might have had theirselves an influence on the primary outcome of the study (30-day mortality); (ii) each ICU had a dedicated infectious diseases consultant referring to the same well-established consultation system, thus assuring the same clinical and therapeutic approach to infections in both cases and controls. Furthermore, it represents a real-life clinical experience providing useful suggestions to clinicians about the management of a difficult-to-treat infection such as septic shock caused by CR-Kp and $\mathrm{CR}-\mathrm{Ab}$.

\section{Materials and Methods}

We performed a retrospective, observational case:control study (1:2) in patients with septic shock caused by CR-Kp or CR-Ab hospitalized in two different ICUs [IRCCS Neuromed for cases and Sapienza University (Rome, Italy) for controls, the latter derived from a historical cohort of patients [6]. Both ICUs have a dedicated Infectious Diseases consultant referring to a well-established consultation system at Policlinico Umberto I, Sapienza University of Rome, with the same clinical and therapeutic approach [49-51] (Supplementary Figure S1). Cases included patients with septic shock receiving intravenous NAC in combination with antimicrobials, controls included patients with septic shock not receiving NAC. For every case, two matched controls were randomly selected from patients who did not receive NAC. Cases and controls were matched for age, SAPS II score, causative agent and source of infection. Data collection for cases was blinded for the outcome. Inclusion criteria were: (i) ICU admission, (ii) presence of septic shock during ICU stay, (iii) laboratory documented and confirmed infection by CR-Kp or CR-Ab and iv) intravenous administration of NAC for cases, whereas exclusion criteria were (i) a documented infection localized to the central nervous system at admission or during hospital stay, (ii) age under 18 years old or (iii) missing key data. 
The Ethical Commitees approved the study (no. 4547-2017 for Sapienza; approval 20 March 2019 for IRCCS Neuromed) whereas informed consent was waived due to the retrospective nature of the research.

\subsection{Baseline Assessment}

Patient data were extracted from medical records and from hospital computerized databases or clinical charts. The following information was reviewed: demographics, clinical and laboratory findings, comorbid conditions, microbiological data, duration of ICU and hospital stay, incidence of infections during hospitalization, treatments and procedures administered during hospitalization and/or in the 90 days prior to infection, classes of antibiotics received on admission and/or after admission before a positive culture of a biological sample was obtained, the simplified acute physiology score II (SAPS II) at the time of infection, source of infection, antibiotic regimens used for CR-Ab or CR-Kp infections, and 30-day mortality. According to both hospital's guidelines, colonization with $\mathrm{CR}-\mathrm{Kp}$ and $\mathrm{CR}-\mathrm{Ab}$ strains was routinely evaluated by rectal swab, respiratory specimens and urine culture at the time of ICU admission and every week afterwards.

\subsection{Definitions}

Infections were defined according to the standard definitions of the ECDC [52] and septic shock was defined according to the SEPSIS-3 criteria definition, a subset of sepsis with persisting hypotension requiring vasopressors to maintain mean arterial pressure of $65 \mathrm{mmHg}$ or greater and having a serum lactate level greater than $2 \mathrm{mmol} / \mathrm{L}$ despite adequate volume resuscitation [53].

A CR-Ab or CR-Kp infection was defined as clinical signs of infection and culture of blood, urine, cerebrospinal fluid or a biological sample from skin and skin structures, lung, or abdomen yielding a CR-Ab or a CR-Kp strain.

Infection onset was defined as the date of collection of the index culture (i.e., the first blood culture that yielded the study isolate). Infections were classified as hospital acquired if the index culture had been collected $>48 \mathrm{~h}$ after hospital admission and no signs or symptoms of infection had been noted at admission. Primary bloodstream infection (BSI) was defined as BSI occurring in patients without a recognized source of infection.

The severity of clinical conditions was determined by using SAPS II score calculated at the time of septic shock onset. Length of hospital and ICU stay were calculated as the number of days from the date of admission to the date of discharge or death.

Depending on the number of drugs used (one or more), treatment regimens were classified as monotherapy or combination therapy. Definitive antibiotic therapy was defined as the definitive antimicrobial treatment based on in vitro CR-Ab or CR-Kp isolates susceptibilities. Antibiotic regimens were also classified according to the following: one antibiotic displaying in vitro activity, and two or more antibiotics displaying in vitro activity. Time to initial definitive therapy was the time between infection onset and initial definitive therapy.

Intravenous NAC was administered in patients with respiratory conditions characterized by excessive and/or thick mucus production as soon as signs of a possible infection developed (i.e., at the very early phase of infection) as adjunctive therapy and stopped together with antibiotic therapy. Dosages of intravenous NAC ranged from 1200 to $3000 \mathrm{mg} /$ die, according to treating physicians. Intravenous NAC was administered in saline solution with 30-60 min infusion rate.

\subsection{Statistical Analysis}

Continuous variables were compared using Student's $t$ test or Mann-Whitney U test and were described as mean \pm standard deviation (SD) or as median and interquartile range (IQR) according to whether the distribution of the variables was normal or nonnormal. Chi-squared test $(\chi 2)$ and Fisher's exact test were used to compare categorical variables. Univariate and multivariate analyses were performed to evaluate factors related to 30 -days mortality. Variables with a $p$ value two-sided $<0.05$ were considered statistically 
significant. The results obtained were analyzed using a commercially available statistical software package (version 15, STATA Corp, College Station, TX, USA: StataCorp LLC).

\section{Conclusions}

In conclusion, in the challenging context of increasing antimicrobial resistance and restricted therapeutic options, this study suggests that a combined use of NAC plus antibiotics might reduce the 30-day mortality rate in ICU patients with septic shock caused by CR-Kp and CR-Ab. Therefore, our preliminary data seem to encourage further clinical investigations on the role of NAC as an adjuvant therapy in ICU patients with septic shock due to multi-drug resistant Gram-negative bacilli.

Supplementary Materials: The following are available online at https://www.mdpi.com/2079 $-6382 / 10 / 3 / 271 / s 1$, Figure S1: Treatment protocol in critically ill patients with suspected Gramnegative infection implemented by Infectious Diseases consultants at the Intensive Care Unit of IRCCS Neuromed (Pozzilli) and Sapienza University of Rome.

Author Contributions: Conceptualization, A.O. and M.V.; methodology, A.O.; formal analysis, D.A.F.; data collection: A.B., A.R., F.C., G.C., F.A.; writing—original draft preparation, A.O.; writingreview and editing, M.V., C.M.M.; supervision, C.M.M., M.V. All authors have read and agreed to the published version of the manuscript.

Funding: This research received no external funding.

Institutional Review Board Statement: The study was conducted according to the guidelines of the Declaration of Helsinki, and approved by the Institutional Review of Sapienza (no. 4547-2017) and IRCCS Neuromed (approval data 20 March 2019).

Informed Consent Statement: The study was conducted according to the guidelines of the Declaration of Helsinki, and approved by the Institutional Review Board of IRCCS Neuromed for cases and of Sapienza University of Rome for controls. Informed consent was waived due to the retrospective nature of the research.

Data Availability Statement: The data used to support the findings of this study are available from the corresponding author upon request.

Acknowledgments: The authors thank the nursing staff for their contribution.

Conflicts of Interest: The authors declare no conflict of interest.

\section{References}

1. Kang, C.-I.; Kim, S.-H.; Park, W.B.; Lee, K.-D.; Kim, H.-B.; Kim, E.-C.; Oh, M.-D.; Choe, K.-W. Bloodstream Infections Caused by Antibiotic-Resistant Gram-Negative Bacilli: Risk Factors for Mortality and Impact of Inappropriate Initial Antimicrobial Therapy on Outcome. Antimicrob. Agents Chemother. 2005, 49, 760-766. [CrossRef] [PubMed]

2. Garnacho-Montero, J.; Dimopoulos, G.; Poulakou, G.; Akova, M.; Cisneros, J.M.; de Waele, J.; Petrosillo, N.; Seifert, H.; Timsit, J.F.; Vila, J.; et al. Task force on management and prevention of Acinetobacter baumannii infections in the ICU. Intensiv. Care Med. 2015, 41, 2057-2075. [CrossRef] [PubMed]

3. Cassini, A.; Högberg, L.D.; Plachouras, D.; Quattrocchi, A.; Hoxha, A.; Simonsen, G.S.; Colomb-Cotinat, M.; Kretzschmar, M.E.; Devleesschauwer, B.; Cecchini, M.; et al. Attributable deaths and disability-adjusted life-years caused by infections with antibiotic-resistant bacteria in the EU and the European Economic Area in 2015: A population-level modelling analysis. Lancet Infect. Dis. 2019, 19, 56-66. [CrossRef]

4. Dickinson, J.D.; Kollef, M.H. Early and Adequate Antibiotic Therapy in the Treatment of Severe Sepsis and Septic Shock. Curr. Infect. Dis. Rep. 2011, 13, 399-405. [CrossRef] [PubMed]

5. Busani, S.; Serafini, G.; Mantovani, E.; Venturelli, C.; Giannella, M.; Viale, P.; Mussini, C.; Cossarizza, A.; Girardis, M. Mortality in Patients with Septic Shock by Multidrug Resistant Bacteria. J. Intensiv. Care Med. 2017, 34, 48-54. [CrossRef]

6. Russo, A.; Giuliano, S.; Ceccarelli, G.; Alessandri, F.; Giordano, A.; Brunetti, G.; Venditti, M. Comparison of Septic Shock Due to Multidrug-Resistant Acinetobacter baumanniior Klebsiella pneumoniae Carbapenemase-Producing K. pneumoniae in Intensive Care Unit Patients. Antimicrob. Agents Chemother. 2018, 62, e02562-17. [CrossRef]

7. Falcone, M.; Bassetti, M.; Tiseo, G.; Giordano, C.; Nencini, E.; Russo, A.; Graziano, E.; Tagliaferri, E.; Leonildi, A.; Barnini, S.; et al. Time to appropriate antibiotic therapy is a predictor of outcome in patients with bloodstream infection caused by KPC-producing Klebsiella pneumoniae. Crit. Care 2020, 24, 1-12. [CrossRef] 
8. Marik, P.E.; Khangoora, V.; Rivera, R.; Hooper, M.H.; Catravas, J. Hydrocortisone, Vitamin C, and Thiamine for the Treatment of Severe Sepsis and Septic Shock. Chest 2017, 151, 1229-1238. [CrossRef]

9. Victor, V.M.; Rocha, M.; de la Fuente, M. Immune cells: Free radicals and antioxidants in sepsis. Int. Immunopharmacol. 2004, 4, 327-347. [CrossRef]

10. Heming, N.; Lamothe, L.; Ambrosi, X.; Annane, D. Emerging drugs for the treatment of sepsis. Expert Opin. Emerg. Drugs 2016, 21, 27-37. [CrossRef]

11. Pinsky, M.R. Antioxidant therapy for severe sepsis: Promise and perspective. Crit. Care Med. 2003, 31, 2697-2698. [CrossRef] [PubMed]

12. Ergin, B.; Guerci, P.; Zafrani, L.; Nocken, F.; Kandil, A.; Gurel-Gurevin, E.; Demirci-Tansel, C.; Ince, C. Effects of N-acetylcysteine (NAC) supplementation in resuscitation fluids on renal microcirculatory oxygenation, inflammation, and function in a rat model of endotoxemia. Intensiv. Care Med. Exp. 2016, 4, 29. [CrossRef]

13. Angus, D.C.; van der Poll, T. Severe Sepsis and Septic Shock. N. Engl. J. Med. 2013, 369, 840-851. [CrossRef]

14. Ait-Oufella, H.; Maury, E.; Lehoux, S.; Guidet, B.; Offenstadt, G. The endothelium: Physiological functions and role in microcirculatory failure during severe sepsis. Intensiv. Care Med. 2010, 36, 1286-1298. [CrossRef] [PubMed]

15. Ince, C.; Mayeux, P.R.; Nguyen, T.; Gomez, H.; Kellum, J.A.; Ospina-Tascón, G.A.; Hernandez, G.; Murray, P.; de Backer, D. The Endothelium in Sepsis. Shock 2016, 45, 259-270. [CrossRef] [PubMed]

16. Ince, C. The microcirculation is the motor of sepsis. Crit. Care 2005, 9, S13-S19. [CrossRef]

17. Chertoff, J. N-Acetylcysteine's Role in Sepsis and Potential Benefit in Patients with Microcirculatory Derangements. J. Intensiv. Care Med. 2018, 33, 87-96. [CrossRef]

18. Sadowska, A.M.; Verbraecken, J.; Darquennes, K.; de Backer, W.A. Role of N-acetylcysteine in the management of COPD. Int. J. Chronic Obstr. Pulm. Dis. 2006, 1, 425-434. [CrossRef]

19. Green, J.L.; Heard, K.J.; Reynolds, K.M.; Albert, D. Oral and Intravenous Acetylcysteine for Treatment of Acetaminophen Toxicity: A Systematic Review and Meta-analysis. West. J. Emerg. Med. 2013, 14, 218-226. [CrossRef] [PubMed]

20. Blasi, F.; Page, C.; Rossolini, G.M.; Pallecchi, L.; Matera, M.G.; Rogliani, P.; Cazzola, M. The effect of N -acetylcysteine on biofilms: Implications for the treatment of respiratory tract infections. Respir. Med. 2016, 117, 190-197. [CrossRef] [PubMed]

21. Pollini, S.; Boncompagni, S.; di Maggio, T.; di Pilato, V.; Spanu, T.; Fiori, B.; Blasi, F.; Aliberti, S.; Sergio, F.; Rossolini, G.M.; et al. In vitro synergism of colistin in combination with $\mathrm{N}$-acetylcysteine against Acinetobacter baumannii grown in planktonic phase and in biofilms. J. Antimicrob. Chemother. 2018, 73, 2388-2395. [CrossRef]

22. Mascellino, M.; de Angelis, M.; Miele, M.C.; Stringaro, A.R.; Colone, M.; Oliva, A. Potential Role of N-Acetyl-Cysteine Towards Mul-ti-Drug Resistant Acinetobacter baumannii and Klebsiella pneumoniae. In Proceedings of the ASM Microbe, San Francisco, CA, USA, 20-24 June 2019; p. AAR02-637.

23. Parry, M.F.; Neu, H.C. Effect of N-acetylcysteine on antibiotic activity and bacterial growth in vitro. J. Clin. Microbiol. 1977, 5, 58-61.

24. Aslam, S.; Darouiche, R.O. Role of Antibiofilm-Antimicrobial Agents in Controlling Device-Related Infections. Int. J. Artif. Organs 2011, 34, 752-758. [CrossRef] [PubMed]

25. Marchese, A.; Bozzolasco, M.; Gualco, L.; Debbia, E.A.; Schito, G.C.; Schito, A.M. Effect of fosfomycin alone and in combination with $\mathrm{N}$-acetylcysteine on E. coli biofilms. Int. J. Antimicrob. Agents 2003, 22, 95-100. [CrossRef]

26. Oliva, A.; de Angelis, M.; Costantini, S.; Mascellino, M.T.; Mastroianni, C.M.; Vullo, V. High activity of N-acetylcysteine in combination with beta-lactam antibiotics against carbapenem-resistant Acinetobater baumannii. In Proceedings of the ECCMID 2018, Madrid, Spain, 21-24 April 2018.

27. Rodríguez-Rosado, A.I.; Valencia, E.Y.; Rodríguez-Rojas, A.; Costas, C.; Galhardo, R.S.; Rodríguez-Beltrán, J.; Blázquez, J. $\mathrm{N}$-acetylcysteine blocks SOS induction and mutagenesis produced by fluoroquinolones in Escherichia coli. J. Antimicrob. Chemother. 2019, 74, 2188-2196. [CrossRef] [PubMed]

28. Garozzo, A.; Tempera, G.; Ungheri, D.; Timpanaro, R.; Castro, A. N-Acetylcysteine Synergizes with Oseltamivir in Protecting Mice from Lethal Influenza Infection. Int. J. Immunopathol. Pharmacol. 2007, 20, 349-354. [CrossRef] [PubMed]

29. Geiler, J.; Michaelis, M.; Naczk, P.; Leutz, A.; Langer, K.; Doerr, H.-W.; Cinatl, J. N-acetyl-l-cysteine (NAC) inhibits virus replication and expression of pro-inflammatory molecules in A549 cells infected with highly pathogenic H5N1 influenza A virus. Biochem. Pharmacol. 2010, 79, 413-420. [CrossRef] [PubMed]

30. Ghezzi, P.; Ungheri, D. Synergistic Combination of N-Acetylcysteine and Ribavirin to Protect from Lethal Influenza Viral Infection in a Mouse Model. Int. J. Immunopathol. Pharmacol. 2004, 17, 99-102. [CrossRef]

31. Hsu, B.-G.; Lee, R.-P.; Yang, F.-L.; Harn, H.-J.; Chen, H.I. Post-treatment with $N$-acetylcysteine ameliorates endotoxin shockinduced organ damage in conscious rats. Life Sci. 2006, 79, 2010-2016. [CrossRef]

32. Spies, C.; Giese, C.; Meier-Hellmann, A.; Specht, M.; Hannemann, L.; Schaffartzik, W.; Reinhart, K. Einfluss der prophylaktischen Gabe von N-Azetylzystein auf klinische Indikatoren der Gewebeoxygenierung unter Hyperoxie bei kardialen Risikopatienten. Anaesthesist 1996, 45, 343-350. [CrossRef]

33. Spapen, H.; Zhang, H.; Demanet, C.; Vleminckx, W.; Vincent, J.-L.; Huyghens, L. Does N-Acetyl-L-Cysteine Influence Cytokine Response During Early Human Septic Shock? Chest 1998, 113, 1616-1624. [CrossRef] [PubMed]

34. Ortolani, O.; Conti, A.; de Gaudio, A.R.; Masoni, M.; Novelli, G. Protective Effects of N-Acetylcysteine and Rutin on the Lipid Peroxidation of the Lung Epithelium during the Adult Respiratory Distress Syndrome. Shock 2000, 13, 14-18. [CrossRef] [PubMed] 
35. Rank, N.; Michel, C.; Haertel, C.; Med, C.; Lenhart, A.; Welte, M.; Meier-Hellmann, A.; Spies, C. N-acetylcysteine increases liver blood flow and improves liver function in septic shock patients: Results of a prospective, randomized, double-blind study. Crit. Care Med. 2000, 28, 3799-3807. [CrossRef]

36. Paterson, R.L.; Galley, H.F.; Webster, N.R. The effect of N-acetylcysteine on nuclear factor-kB activation, interleukin-6, interleukin8, and intercellular adhesion molecule-1 expression in patients with sepsis. Crit. Care Med. 2003, 31, 2574-2578. [CrossRef]

37. Szakmany, T.; Hauser, B.; Radermacher, P. N-acetylcysteine for sepsis and systemic inflammatory response in adults. Cochrane Database Syst. Rev. 2012, 2012, CD006616. [CrossRef] [PubMed]

38. Aisa-Alvarez, A.; Soto, M.E.; Guarner-Lans, V.; Camarena-Alejo, G.; Franco-Granillo, J.; Martínez-Rodríguez, E.A.; Ávila, R.G.; Pech, L.M.; Pérez-Torres, I. Usefulness of Antioxidants as Adjuvant Therapy for Septic Shock: A Randomized Clinical Trial. Medicina 2020, 56, 619. [CrossRef]

39. Falcone, M.; Russo, A.; Iacovelli, A.; Restuccia, G.; Ceccarelli, G.; Giordano, A.; Farcomeni, A.; Morelli, A.; Venditti, M. Predictors of outcome in ICU patients with septic shock caused by Klebsiella pneumoniae carbapenemase-producing K. pneumoniae. Clin. Microbiol. Infect. 2016, 22, 444-450. [CrossRef]

40. Lopez-Cortes, L.E.; Cisneros, J.M.; Fernández-Cuenca, F.; Bou, G.; Tomas, M.; Garnacho-Montero, J.; Pascual, A.; MartinezMartinez, L.; Vilá, J.; Pachón, J.; et al. Monotherapy versus combination therapy for sepsis due to multidrug-resistant Acinetobacter baumannii: Analysis of a multicentre prospective cohort. J. Antimicrob. Chemother. 2014, 69, 3119-3126. [CrossRef]

41. Zafarullah, M.; Li, W.Q.; Sylvester, J.; Ahmad, M. Molecular mechanisms of N -acetylcysteine actions. Cell. Mol. Life Sci. 2003, 60, 6-20. [CrossRef]

42. Harman, L.S.; Mottle, C.; Mason, R.P. Free radical metabolites of L-cysteine oxidation. J. Biol. Chem. 1984, $259,5606-5611$. [CrossRef]

43. Kumar, A.; Roberts, D.; Wood, K.E.; Light, B.; Parrillo, J.E.; Sharma, S.; Suppes, R.; Feinstein, D.; Zanotti, S.; Taiberg, L.; et al. Duration of hypotension before initiation of effective antimicrobial therapy is the critical determinant of survival in human septic shock. Crit. Care Med. 2006, 34, 1589-1596. [CrossRef]

44. Ferrer, R.; Artigas, A.; Suarez, D.; Palencia, E.; Levy, M.M.; Arenzana, A.; Pérez, X.L.; Sirvent, J.-M. Effectiveness of Treatments for Severe Sepsis. Am. J. Respir. Crit. Care Med. 2009, 180, 861-866. [CrossRef]

45. Levy, M.M.; Artigas, A.; Phillips, G.S.; Rhodes, A.; Beale, R.; Osborn, T.; Vincent, J.-L.; Townsend, S.; Lemeshow, S.; Dellinger, R.P. Outcomes of the Surviving Sepsis Campaign in intensive care units in the USA and Europe: A prospective cohort study. Lancet Infect. Dis. 2012, 12, 919-924. [CrossRef]

46. Tumbarello, M.; Viale, P.; Viscoli, C.; Trecarichi, E.M.; Tumietto, F.; Marchese, A.; Spanu, T.; Ambretti, S.; Ginocchio, F.; Cristini, F.; et al. Predictors of Mortality in Bloodstream Infections Caused by Klebsiella pneumoniae Carbapenemase-Producing K. pneumoniae: Importance of Combination Therapy. Clin. Infect. Dis. 2012, 55, 943-950. [CrossRef]

47. Tumbarello, M.; Trecarichi, E.M.; de Rosa, F.G.; Giannella, M.; Giacobbe, D.R.; Bassetti, M.; Losito, A.R.; Bartoletti, M.; del Bono, V.; Corcione, S.; et al. Infections caused by KPC-producing Klebsiella pneumoniae: Differences in therapy and mortality in a multicentre study. J. Antimicrob. Chemother. 2015, 70, 2133-2143. [CrossRef] [PubMed]

48. Russo, A.; Bassetti, M.; Ceccarelli, G.; Carannante, N.; Losito, A.R.; Bartoletti, M.; Corcione, S.; Granata, G.; Santoro, A.; Giacobbe, D.R.; et al. Bloodstream infections caused by carbapenem-resistant Acinetobacter baumannii: Clinical features, therapy and outcome from a multicenter study. J. Infect. 2019, 79, 130-138. [CrossRef]

49. Augustine, M.R.; Testerman, T.L.; Justo, J.A.; Bookstaver, P.B.; Kohn, J.; Albrecht, H.; Al-Hasan, M.N. Clinical Risk Score for Prediction of Extended-Spectrum $\beta$-Lactamase-Producing Enterobacteriaceae in Bloodstream Isolates. Infect. Control. Hosp. Epidemiol. 2016, 38, 266-272. [CrossRef]

50. Gutiérrez-Gutiérrez, B.; Salamanca, E.; de Cueto, M.; Hsueh, P.-R.; Viale, P.; Paño-Pardo, J.R.; Venditti, M.; Tumbarello, M.; Daikos, G.; Pintado, V.; et al. A Predictive Model of Mortality in Patients with Bloodstream Infections due to Carbapenemase-Producing Enterobacteriaceae. Mayo Clin. Proc. 2016, 91, 1362-1371. [CrossRef] [PubMed]

51. Giannella, M.; Trecarichi, E.; de Rosa, F.; del Bono, V.; Bassetti, M.; Lewis, R.; Losito, A.; Corcione, S.; Saffioti, C.; Bartoletti, M.; et al. Risk factors for carbapenem-resistant Klebsiella pneumoniae bloodstream infection among rectal carriers: A prospective observational multicentre study. Clin. Microbiol. Infect. 2014, 20, 1357-1362. [CrossRef] [PubMed]

52. European Centre for Disease Prevention and Control (ECDC). European Antimicrobial Resistance Surveillance Network (EARSNet). Available online: https:/ / www.ecdc.europa.eu/en/home (accessed on 20 January 2021).

53. Singer, M.; Deutschman, C.S.; Seymour, C.W.; Shankar-Hari, M.; Annane, D.; Bauer, M.; Bellomo, R.; Bernard, G.R.; Chiche, J.-D.; Coopersmith, C.M.; et al. The Third International Consensus Definitions for Sepsis and Septic Shock (Sepsis-3). JAMA 2016, 315, 801-810. [CrossRef] [PubMed] 